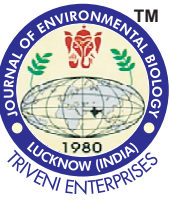

DOI : http://doi.org/10.22438/jeb/39/5/MRN-536

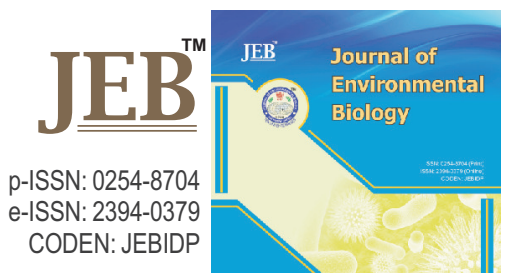

\title{
Synergic antiobesity effects of bitter melon water extract and platycodin-D in genetically obese mice
}

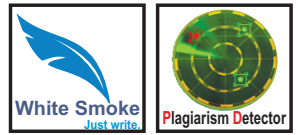

\section{Authors Info}

J.H. Sohn', J.W. Kim², G.W. Jung', D.C. Park', S.B. Moon ${ }^{2}$, H.R. Cho', S.K. Ku and J.S. Choi" ${ }^{1 *}$

'Division of Bioindustry, College of Medical and Life Sciences, Silla University, Sasang-gu, Busan, 46958, Republic of Korea

${ }^{2}$ Glucan corp. \#305 Marine BioIndustry Development Center, Hoenggye-ri 27, Gijan-gun, Busan, 46048, Republic of Korea

${ }^{3}$ Department of Anatomy and Histology, College of Oriental Medicine, Daegu Haany University, 290 Yugok-dong, Gyeongsan-si, Gyeongsanbuk-do, 38610, Republic of Korea

${ }^{*}$ Corresponding Author Email : jsc1008@silla.ac.kr

Key words

Adipokines $\mathrm{db} / \mathrm{db}$ mouse

Momordica charantia

Obesity

Platycodin

Publication Info

Paper received: 14.12 .2016

Revised received : 20.02.2017

Re-revised received : 23.11.2017

Accepted: 27.12.2017

\begin{abstract}
Aim: Momordica charantia water extract and platycodin-D are potent hypoglycemic and hypolipemic agents. In the present study, anti-obesity effects of these agents were investigated in various proportions.

Methodology: Test agents were administered orally $\left(200 \mathrm{mg} \mathrm{kg}^{-1} \mathrm{~b}\right.$.wt.) once a day for 28 days to $\mathrm{db} / \mathrm{m}$ and $d b / d b$ mice. There were 15 groups ( $n=7$ per group): $d b / m$, vehicle control, $M$. charantia alone platycodin-D alone, and the various $M$. charantia : platycodin-D ratio $\mathrm{db} / \mathrm{db}$ groups. Animals were assigned to groups according to body weight and blood glucose level one day before initiation of dosing. After 28 days of dosing, changes in body weight, blood glucose, epididymal fat weight, serum leptin, adipose adiponectin and liver triglycerides were recorded.
\end{abstract}

Results: Prior to the initiation of dosing, $d b / d b$ mice showed marked obesity compared to $\mathrm{db} / \mathrm{m}$ mice (normal littermates), together with severe hyperglycemia. Epididymal fat weight, serum leptin and liver triglycerides were significantly increased in obese versus intact controls $(p<0.01)$, with significant decrease in serum adiponectin and adipose adiponectin content also seen in the latter group $(p<0.01)$. However, these obesity-related changes were significantly decreased by treatment with $M$. charantia water extract alone or platycodin-D alone, as well as in combination at all of the tested ratios and more favorable effects were detected in some of the mixed formula groups compared to those of $M$. charantia water extract alone and platycodin-D alone. Among the 11 mixed formulas, $M$. charantia water extract: platycodin-D at a ratio of 1:4 showed the most dramatic obesity-inhibiting effects.

Interpretation: Based on the results of this study, it can be concluded that appropriate mixtures of $M$. charantia water extract and platycodin-D exert substantial, synergic antiobesity effects in obese diabetic mice.

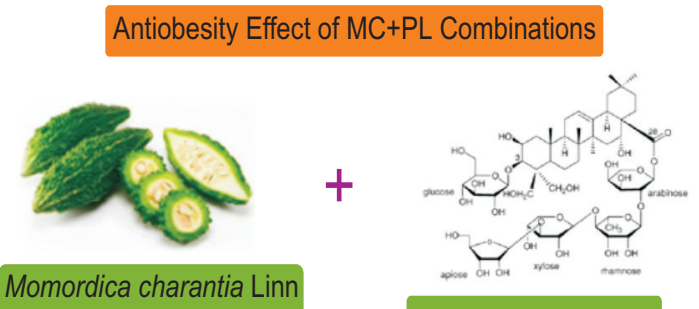

Platycodin-D (PL)

- $1: 1,1: 2,1: 4,1: 6,1: 8,1: 10,2: 1,4: 1,6: 1$, MC:PL combination ratios $8: 1$ and $10: 1$

- $d b / m$ (control) and $d b / d b$ mice, 15 groups - $n=7$ per group

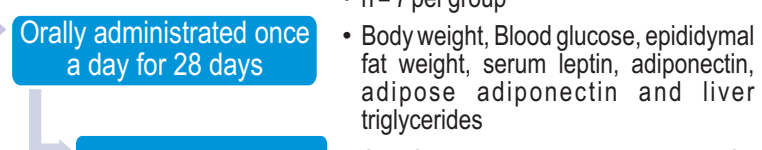

Biomarkers - Significant increase in epididymal fat weight, serum leptin and liver triglycerides, $(p<0.01)$

Results - Significant decrease in serum adiponectin and adipose adiponectin $(p<0.01)$

- MC: PL ratio (1:4) sowed most dramatic obesity-inhibiting effect

Appropriate MC:PLcombination exerted synergistic obesity-inhibiting effect in obese diabetic mice 


\section{Introduction}

Recently, there has been a global increase in the incidence of obesity associated with type 2 diabetes, the development of which appears to result from a high-calorie diet intake coupled with physical inactivity (James et al., 2001). It is projected that the incidence of diabetes-related obesity will double to over 300 million cases by 2025 (Zimmet, 2003). Vigorous efforts have been directed toward delineating the relationship between increased adiposity and insulin resistance. Adipokines (Mitchell et al., 2005), including leptin (Wolf et al., 2002) and adiponectin (Yamauchi et al., 2003), are secreted by adipocytes and may modulate insulin sensitivity. In turn, insulin sensitivity in type 2 diabetes is associated with multiple signaling events, following phosphorylation of insulin receptors and several other molecules (Sakaue et al., 2003).

The $d b / d b$ mouse is hyperleptinemic and thus develops obesity and severe type 2 diabetes, partly due to a functional defect in the long-form leptin receptor (Ob-Rb); this receptor plays a significant role in regulating food intake and controlling body weight (Sharma et al., 2003). Therefore, the genetically obese $d b / d b$ mouse has been used in field tests of various pharmaceuticals, including anti-type II diabetes and -obesity agents (Neary et al., 2005). Generally, the antiobesity effects of test agents have been evaluated according to their effects on body weight, fat weight and organ and serum lipid profiles (including various adipokines, such as leptin and adiponectin) (Mitchell et al., 2005).

Momordica charantia (family Cucurbitaceae), more commonly known as bitter melon, bitter gourd, karela or balsam pear, is a popular vegetable that is grown widely in tropical areas. In addition to culinary usage, it is also used in folklore medicine. Although M. charantia water extract has been found to possess antiviral, antibacterial, anti-HIV, anticancer and immunomodulatory properties, attention has typically been focused on its blood glucose-lowering effect (Basch et al., 2003; Efird et al., 2014). This effect was demonstrated in streptozotocininduced diabetic rats (Ahmed et al., 2004) and diet-induced obese rats (Chen et al., 2003). In addition, M. charantia water extract has shown promising effects for both preventing and delaying the progression of diabetic complications (e.g., nephropathy, neuropathy, gastroparesis, cataract and insulin resistance) in experimental animals (Rathi et al., 2002), in turn mediated by the insulin-like activity of polypeptide-p (phytoinsulin) as well as enhanced pancreatic beta cell of charantin expression and glucose utilization (Sarkar et al., 1996). Freezedried $M$. charantia juice feeding leads to a general decrease in accumulated tissue fat and blood glucose, effects that are in part mediated by enhanced sympathetic activity and lipolysis in rats (Chen and Li, 2005). Additionally, chronic BM feeding leads to a general decrease in tissue fat accumulation and blood glucose, mediated in part by enhanced sympathetic activity and lipolysis
(Chen and Li, 2005). Park and Heo (2011) found that bitter melon (Momordica charantia) extracts had beneficial effects on body weight change and lipid composition in C57/BL6J mice fed with high-fat diet. Recently, the beneficial role of bitter melon supplementation in addressing obesity and related complications in metabolic syndrome was observed (Alam et al., 2015).

Platycodi radix, the root of Platycodon grandiflorum, has been used traditionally as an expectorant and remedy for bronchitis, tonsillitis, laryngitis and suppurative dermatitis in Korea, China and Japan. In China and Korea, the fresh roots of $P$. grandiflorum are eaten in pickled form to prevent obesity (Han et al., 2000). It has been reported that platycodin-D, a major component of Platycodi radix (Han et al., 2002), shows antiobesity, -diabetes and -hypolipemia effects (Han et al., 2000, 2002), evidenced by improved insulin resistance in obese Zucker rats (Kim et al., 2000). However, the effective dose against obesity was much higher than the ideal dosage of an antiobesity agent: $0.5 \mathrm{~g} \mathrm{l}^{-1}$ in vitro and at least $244 \mathrm{mg} \mathrm{kg}^{-1}$ in animals (Han et al., 2000).

A number of oral anti-diabetic medicines are currently in use, or are in development, including thiazolidinedione (TZD) and metformin, both of which improve insulin resistance. Metformin inhibits hepatic glucose production via reduced gluconeogenesis (Seufert et al., 2004), and effectively inhibits high fat diet-induced obesity in mice (Park et al., 2005). However, currently available pharmacological agents for the treatment of diabetes and diabetes-related obesity have numerous limitations, including various adverse effects and high rates of secondary failure (Inzucchi, 2002). Therefore, diabetic patients and healthcare professionals are interested in complementary, alternative approaches, including the use of medicinal herbs. However, it is very difficult to develop antiobesity agents using such herbs because they have relatively high efficacy dosages in animal experiments and human clinical trials.

In this study, the complementary and alternative treatment for obesity by mixing two potent hypoglycemic and hypolipemic agents: M. charantia water extract and platycodin-D was further explored. To ascertain the optimal ratio, the antiobesity effects of eleven $M$. charantia water extract + platycodin-D mixtures were assessed in obese $\mathrm{db} / \mathrm{db}$ mice at 200 $\mathrm{mg} \mathrm{kg}^{-1}$. Test agents were administered orally once a day for 28 days and changes in body weight, epididymal fat weight, blood glucose, serum leptin, adiponectin, fat adiponectin and liver triglycerides were measured.

\section{Materials and Methods}

Mice and husbandry: In total, 196, genetically obese male $d b / d b$ mice with $\mathrm{C} 57 \mathrm{BL} / \mathrm{KsJ}$ genetic background and 14 lean nondiabetic heterozygous littermates $(\mathrm{db} / \mathrm{m}$ mice, seven weeks of age; Clear Japan Co., Tokyo, Japan) were used following 
acclimatization for seven days. Animals were allocated to polycarbonate cages $\left(n=7\right.$ per cage) in a temperature $\left(20-25^{\circ} \mathrm{C}\right)$ and humidity (40-45\%) controlled room. The light:dark cycle was 12:12 hrs, and standard rodent chow (Samyang, Masan Korea) and water were supplied ad libitum. About half of the animals were selected (seven per group) for the estimation of fasting blood glucose levels and body weight at one day before dosing commenced. The mean fasting blood glucose level in $\mathrm{db} / \mathrm{m}$ mice one day before initial dosing was $102.43 \pm 10.86 \mathrm{mg} \mathrm{dl}^{-1}$, compared to $276.53 \pm 9.17 \mathrm{mg} \mathrm{dl}^{-1}$ in $\mathrm{db} / \mathrm{db}$ mice. Animal care and use was in accordance with the guidelines of our institution and the protocol was approved by the Institutional Animal Care and Use Committee of Silla University (Busan, Korea; approval no. SUACUC-2016-008).

Preparation and administration of drugs: Momordica charantia and Platycodi radix used in this study were purchased from Bonchowon (Seoul, Korea). Briefly, dried M. charantia fruit (containing seeds) was ground using a commercial electronic pulverizer. Approximately, $200 \mathrm{~g}$ of lyophilized MC water extract was prepared from $1,500 \mathrm{~g}$ of ground $M$. charantia and evaporated in $15 \mathrm{I}$ of water for $12 \mathrm{hrs}$ in a commercial rotary vacuum evaporator at $105^{\circ} \mathrm{C}$ (LAB Camp, Daejeon, Korea). The extract was then kept in a programmable freeze dryer (IIShin Lab., Yangju, Korea). The raw sample (100 kg) of Platycodi radix was extracted with methanol and partitioned sequentially with $n$ hexane, chloroform, ethyl acetate and n-butanol. The n-butanol fraction was then subjected to a Diaion HP-20 resin (Mitsubishi Chemical Corp., Tokyo, Japan), and the fractions eluted at $60-80 \%$ of methanol were collected to obtain $90 \mathrm{~g}$ of crude saponins. The crude saponins were further purified by repeated silica gel (Merck, Darmstadt, Germany) chromatography to obtain the purified platycodin-D. This process was repeated several times until a sufficient quantity of platycodin-D was obtained. The purified platycodin-D was identified on the basis of the Rf value from a chromatographic analysis, fast atom bombardment-mass spectrometry (FAB-MS) (nominal mass = $1,225.38$ ) and carbon-13 nuclear magnetic resonance (13CNMR) spectra results and compared with the authentic PL. Purity was assessed based on the high-performance liquid chromatography (HPLC) chromatogram of Zorbax SB-Aq (ODS C18 column; Agilent, Palo Alto, CA, USA) equipped with an evaporative laser scattering detector (Sedex 75; Sedere, Alfortville, France), as described previously (Zhao et al., 2006). The prepared platycodin-D and M. charantia water extract samples were stored in a refrigerator at $4^{\circ} \mathrm{C}$ to protect them from light and degeneration. Then, M. charantia water extract, platycodin-D and 11 M. charantia water extract + platycodin-D mixtures were dissolved in distilled water, and animals were dosed by oral gavage using a sonde attached to $3 \mathrm{ml}$ syringes containing test agents ( $200 \mathrm{mg} \mathrm{kg}^{-1}$ per day for 28 days). The doses, M. charantia water extract + platycodin-D formulations, and dosage schedules are detailed in Table 1.
Body weight changes: Changes in body weight were calculated one day before dosing, at initial dosing and after 1, 7, 14, 21, 27 and 28 days using an automatic electronic balance (Sartorius Co., Ltd., Long Island, NY, USA). At both initial dosing and sacrifice, animals were fasted overnight (only water was available for about $12 \mathrm{hrs}$ ) to reduce interindividual differences in feeding behavior. Body weight gain was calculated by deducting weight at sacrifice with weight at initial dosing.

Estimation of blood glucose: To measure blood glucose level, blood was collected one day before initial dosing, and after 28 days of dosing from the orbital plexus.

Collected blood was deposited into a NaF glucose vacuum tube (Becton Dickinson, Franklin Lakes, NJ, USA) and plasma was separated. Blood glucose levels were detected using an automated blood analyzer (Toshiba 200 FR, Tokyo, Japan). In addition, changes in blood glucose level between initial dosing and after 28 days were calculated by deducting blood level at initial dosing with blood level at sacrifice.

Estimation of epididymal fat weight: The animals were sacrificed by administering $\mathrm{CO}_{2}$ gas in an anesthetizing box (the 7900 induction box, Ugo Basile S. R. L., Gemonio, VA, Italy) according to the method developed by Danneman et al. (1997). After sacrifice, epididymal adipose tissue was removed and weighed to reduce error. The relative percentage of fat weight was calculated by dividing absolute epididymal fat weight the body weight at sacrifice.

Estimation of serum adiponectin levels: To measure serum adiponectin levels, blood was collected at sacrifice from the vena cava after overnight fasting. To separate the serum from the blood, one milli litre sample of venous blood was collected from the vena cava under anesthesia using $\mathrm{CO}_{2}$ gas. All blood samples in a clotting activated serum tube were centrifuged at $600 \mathrm{xg}$ for $10 \mathrm{~min}$ at room temperature using a centrifuge (Thermo Scientific Sorvall Legend Mach 1.6R; Thermo Fisher Scientific, Inc., Waltham, MA, USA). Serum adiponectin levels were detected using a commercially available ELISA kit (Otsuka Co., Ltd., Tokushima, Japan).

Estimation of adiponectin content in epididymal adipose tissue: Adipose tissue adiponectin content was determined by Western blot analysis, as described previously (Fujita et al., 2005). The removed epididymal adipose tissue was homogenized in PBS containing $0.5 \%$ sodium deoxycholate. Homogenates were incubated for 24 hrs at $37^{\circ} \mathrm{C}$. After incubation, the homogenates were centrifuged at $15,000 \mathrm{~g}$ for 10 $\mathrm{min}$. The fat cake was removed by suction and adipose tissue extracts (supernatants) were used for Western blot analysis. Aliquots of the tissue extracts (10 $\mu$ g protein) prepared in sodium dodecyl sulfate (SDS) sample buffer were incubated for $5 \mathrm{~min}$ at $100^{\circ} \mathrm{C}$. Denatured proteins were separated by sodium dodecyl 
sulfate-polyacrylamide gel electrophoresis (SDS-PAGE) and then transferred to polyvinylidene difluoride (PVDF) membranes (Bio-Rad, Hercules, CA, USA). The membranes were incubated with a 1:10,000 dilution of mouse anti-mouse adiponectin monoclonal antibody (Chemicon International, Billerica, MA, USA) for 12 hrs at room temperature and then incubated with a 1:5,000 dilution of horseradish peroxidase-conjugated goat antimouse immunoglobulin $\mathrm{G}(\mathrm{IgG})$ antibody (DAKO, Carpinteria, CA, USA) for $1 \mathrm{hr}$ at room temperature. After incubation, the membranes were soaked in chemiluminescence solution using electrochemiluminescence (ECL) Western blotting detection reagents (Amersham International, Amersham, UK). The membranes were exposed to X-ray film to visualize the adiponectin protein. Signals from the X-ray film were quantified using a charge-coupled device (CCD) image analyzer system (DMI, Daegu, Korea). Adiponectin protein content per $10 \mu \mathrm{g}$ of adipose tissue protein, in intact controls and all dose groups, was normalized to that of obese control using the same assay and expressed as a percentage of the control group.

Estimation of serum leptin levels: To detect serum leptin levels, blood was collected after sacrifice from the vena cava after overnight fasting, and serum was separated from collected blood using general methods. Serum leptin levels were detected using a commercially available radioimmunoassay kit (Linco Research, St. Charles, MO, USA), as described previously (Sahai et al., 2004).

Estimation of liver triglyceride content: Liver samples (50-70 $\mathrm{mg}$ ) were homogenized in $50 \mathrm{mM}$ Tris-HCl buffer (pH 7.4) containing $150 \mathrm{mM} \mathrm{NaCl}, 1 \mathrm{mM}$ EDTA and $1 \mu \mathrm{M}$ PMSF. Triglyceride content in the liver homogenates was measured using a spectrophotometry kit (Thermo DMA, Louisville, CO, USA), as described previously (Sahai et al., 2004).

Statistical analysis: Data were presented as means $\pm S D(n=7$ per group). The Mann Whitney U-Wilcoxon rank sum W test (MW test) was performed using SPSS for Windows software (ver. 6.1.3.; SPSS Inc., Chicago, IL, USA). Differences between intact and obese control were evaluated. To gauge the effectiveness of the test agents, inhibition in all dosing groups compared to that of obese control. The percentage changes are compared to intact control by subtracting the intact control from obese control and then dividing the sum of all intact control. The percentage changes compared to obese control was calculated by subtracting the obese control from the dosing groups and then dividing the sum of all obese control.

\section{Results and Discussion}

Before initial dosing, $\mathrm{db} / \mathrm{db}$ mice showed marked obesity compared to $\mathrm{db} / \mathrm{m}$ mice. Significant increase in body weight were observed throughout the experiment in obese versus intact control $(p<0.01)$ and body weight gain between initial dosing and after 28 days was also significantly greater in obese animals $(p<0.01)$. However, there was significantly less body weight gain between initial dosing and after 28 days in all dosing groups versus obese control $(p<0.01$ or $p<0.05)$. Body weight significantly decreased after 21 days in 1:4 ratio $M$. charantia + platycodin-D group and after 27 days in other groups (including M. charantia alone and platycodin-D alone) compared to, obese control ( $p<0.01$ or $p<0.05$; Table 2 and Fig. 1).

Significant increase in blood glucose levels $(p<0.01)$ and significant changes between initial dosing and after 28 days were detected in obese versus intact control. However, significant decrease in blood glucose levels, and significant changes after 28 days, were detected in all dosing groups compared to obese control $(p<0.01$ or $p<0.05)$, except for platycodin-D alone and 1:10 M. charantia water extract + platycodin-D groups, in which non-significant decrease were detected. More dramatic hypoglycemic effects were detected in all the mixed formulation groups relative to single formulation groups, except for $1: 8$ and 1:10 M. charantia water extract + platycodin-D groups, in which more favorable hypoglycemic effects relative to platycodin-D alone group were detected (Table 3). In the obese control, the blood glucose level one day before initiation of dosing was $185.11 \%$ higher than in the intact control.

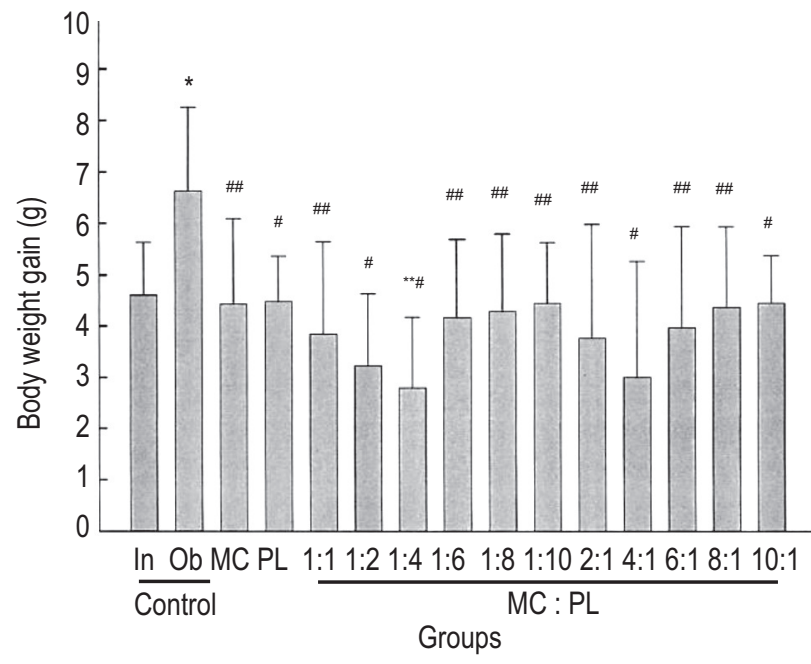

Fig. 1 : Changes in body weight gain after 28 days of test agent administration. In: Intact control: Normoglycemic $(\mathrm{db} / \mathrm{m})$ littermate vehicle control group; Ob: Obese control: Obese diabetic $(\mathrm{db} / \mathrm{db})$ mice vehicle control group; M. charantia : M. charantia $200 \mathrm{mg} \mathrm{kg}^{-1}$ orally dosed obese diabetic group; platycodin-D : platycodin-D $200 \mathrm{mg} \mathrm{kg}^{-1}$ orally dosed obese diabetic group Mixed formula groups (MC:PL); MC:PL: 11 types of MC:PL mixed formula (1:1, 1:2, 1:4, 1:6, 1:8, 1:10, $2: 1,4: 1,6: 1,8: 1$ and $10: 1) 200 \mathrm{mg} \mathrm{kg}^{-1}$ orally dosed obese diabetic groups; Values are mean of seven replicates \pm SD; Body weight gains between at initiation and end of test article 28 day dosing; ${ }^{1)}$ Single formula; ${ }^{2)}$ Mixed formulation; ${ }^{*} p<0.01$ and ${ }^{* *} p<0.05$ compared to that of sham by MW test; ${ }^{*} p<0.01$ and ${ }^{\#} p<0.05$ compared to that of obese control by MW test 
Table 1 : Treatment schedule of Momordica charantia (MC) and Platycodi radix (PL) to genetically obese $\mathrm{db} / \mathrm{db}$ mice

\begin{tabular}{llll}
\hline Groups & & \multicolumn{2}{c}{ Actual dosage $\left(\mathbf{m g ~ k g} \mathbf{~}^{-1}\right)$} \\
\cline { 3 - 4 } & & MC & PL \\
\hline$d b / m$ & Normal littermates & 0 & 0 \\
$d b / d b$ & Vehicle control & 0 & 0 \\
& MC: Single formulation & 200 & 0 \\
PL: Single formulation & 0 & 200 \\
Mixed formulation (MC:PL) & & 100 \\
& $=1: 1$ & 100 & 133.34 \\
& $=1: 2$ & 66.66 & 160 \\
& $=1: 4$ & 40 & 171.43 \\
& $=1: 6$ & 28.57 & 177.78 \\
& $=1: 8$ & 22.22 & 181.82 \\
& $=1: 10$ & 18.18 & 66.66 \\
& $=2: 1$ & 133.34 & 40 \\
& $=4: 1$ & 160 & 28.57 \\
& $=6: 1$ & 171.43 & 22.22 \\
& $=8: 1$ & 177.78 & 18.18 \\
& $=10: 1$ & 181.82 & \\
\hline
\end{tabular}

Animals were dosed by gastric gavage (test agents and vehicle) for four weeks at $200 \mathrm{mg} \mathrm{kg}^{-1}$ in $10 \mathrm{ml}$ of distilled water

Table 2 : Changes in body weight after 28 days of test agent administration in genetically obese $\mathrm{db} / \mathrm{db}$ mice

\begin{tabular}{|c|c|c|c|c|c|c|c|}
\hline \multirow[t]{2}{*}{ Groups } & \multirow[t]{2}{*}{ At dosing $^{1)}$} & \multirow[t]{2}{*}{ Day 1} & \multicolumn{4}{|c|}{ Weeks after dosing } & \multirow[t]{2}{*}{ At sacrifice $^{1)}$} \\
\hline & & & 1 week & 2 weeks & 3 weeks & 4 weeks & \\
\hline \multicolumn{8}{|l|}{ Control } \\
\hline Intact & $23.41 \pm 2.01$ & $25.46 \pm 2.27$ & $27.39 \pm 1.86$ & $28.16 \pm 1.57$ & $29.54 \pm 1.48$ & $30.14 \pm 1.40$ & $28.03 \pm 1.51$ \\
\hline Obese & $40.64 \pm 0.69^{*}$ & $42.63 \pm 0.91^{*}$ & $44.10 \pm 0.94^{*}$ & $46.16 \pm 1.22^{*}$ & $47.70 \pm 1.62^{*}$ & $49.59 \pm 1.79^{*}$ & $47.27 \pm 1.93^{*}$ \\
\hline $\mathrm{MC}^{2)}$ & $40.51 \pm 1.15^{\star}$ & $42.46 \pm 1.40^{*}$ & $43.90 \pm 1.08^{*}$ & $45.27 \pm 1.31^{*}$ & $46.60 \pm 1.32^{*}$ & $47.39 \pm 1.61^{* \text { *\# }}$ & 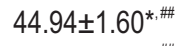 \\
\hline $\mathrm{PL}^{2)}$ & $40.54 \pm 1.61^{*}$ & $42.76 \pm 1.40^{*}$ & $44.89 \pm 1.62^{*}$ & $46.66 \pm 1.88^{*}$ & $47.11 \pm 1.85^{\star}$ & $47.23 \pm 1.26^{*, \# \#}$ & $45.03 \pm 1.33^{*}$ \\
\hline \multicolumn{8}{|l|}{$M C: P^{3)}$} \\
\hline$=1: 1$ & $40.50 \pm 1.87^{\star}$ & $42.51 \pm 1.86^{*}$ & $44.40 \pm 2.02^{*}$ & $45.93 \pm 1.34^{*}$ & $46.34 \pm 1.16^{*}$ & $46.71 \pm 0.89^{*, \#}$ & $44.34 \pm 1.09^{*, \#}$ \\
\hline$=1: 2$ & $40.70 \pm 1.70^{*}$ & $42.81 \pm 1.63^{*}$ & $44.97 \pm 2.30^{*}$ & $45.93 \pm 2.51^{*}$ & $45.97 \pm 1.78^{*}$ & $46.53 \pm 1.39^{*, \#}$ & $43.93 \pm 1.13^{*, \#}$ \\
\hline$=1: 4$ & $40.66 \pm 1.39^{*}$ & $42.76 \pm 1.58^{*}$ & $43.91 \pm 1.37^{\star}$ & $45.36 \pm 1.13^{*}$ & $45.33 \pm 1.28^{*}$ & $45.63 \pm 1.17^{*, \#}$ & $43.44 \pm 1.21^{\text {*\#\# }}$ \\
\hline$=1: 6$ & $40.74 \pm 1.69^{*}$ & $42.69 \pm 1.74^{*}$ & $44.41 \pm 1.55^{\star}$ & $46.33 \pm 1.31^{*}$ & $46.99 \pm 0.95^{\star}$ & $47.07 \pm 1.67^{* \ldots \#}$ & $44.90 \pm 1.70^{*}$ \\
\hline$=1: 8$ & $40.51 \pm 0.69^{*}$ & $42.50 \pm 0.59^{*}$ & $44.27 \pm 0.77^{*}$ & $45.44 \pm 0.96^{*}$ & $46.86 \pm 1.29^{*}$ & $47.29 \pm 1.56^{*}$ & $44.80 \pm 1.50^{*}$ \\
\hline$=1: 10$ & $40.56 \pm 0.87^{\star}$ & $42.77 \pm 1.04^{*}$ & $44.23 \pm 0.90^{*}$ & $45.94 \pm 0.57^{*}$ & $46.67 \pm 1.03^{*}$ & $47.33 \pm 1.38^{* \text { *\# }}$ & $45.00 \pm 1.46^{*}$ \\
\hline$=2: 1$ & $40.83 \pm 1.51^{*}$ & $42.74 \pm 1.36^{*}$ & $44.54 \pm 1.44^{*}$ & $45.87 \pm 1.48^{*}$ & $46.99 \pm 1.29^{*}$ & $47.14 \pm 1.17^{*}$ & $44.59 \pm 1.73^{\star}$ \\
\hline$=4: 1$ & $40.60 \pm 1.43^{*}$ & $42.70 \pm 1.52^{*}$ & $44.11 \pm 1.63^{*}$ & $45.81 \pm 1.76^{*}$ & $46.19 \pm 1.74^{*}$ & $46.14 \pm 1.67^{\text {*\# }}$ & $43.60 \pm 1.93^{\text {*.\# }}$ \\
\hline$=6: 1$ & $40.80 \pm 1.47^{\star}$ & $42.91 \pm 1.95^{\star}$ & $44.86 \pm 1.50^{*}$ & $46.04 \pm 1.06^{*}$ & $47.17 \pm 0.97^{*}$ & $47.13 \pm 1.32^{*}$ & $44.76 \pm 1.49^{*}$ \\
\hline$=8: 1$ & $40.70 \pm 1.18^{*}$ & $42.71 \pm 1.34^{*}$ & $44.53 \pm 1.28^{*}$ & $46.21 \pm 1.13^{*}$ & $47.14 \pm 0.88^{*}$ & $47.37 \pm 0.81^{*}$ & $45.06 \pm 1.05^{\star}$ \\
\hline$=10: 1$ & $40.51 \pm 1.43^{*}$ & $42.44 \pm 1.44^{*}$ & $44.33 \pm 1.61^{*}$ & $45.99 \pm 1.56^{*}$ & $46.71 \pm 1.33^{*}$ & $47.36 \pm 1.22^{*}$ & $44.96 \pm 0.98^{*}$ \\
\hline
\end{tabular}

Values are mean of seven replicates $\pm S D ;{ }^{1)}$ Overnight fasted; ${ }^{2)}$ Single formulation; ${ }^{3)}$ Mixed formulation; ${ }^{*} p<0.01$ compared to that of intact control by MW test; ${ }^{*} p<0.01$ and ${ }^{\#} p<0.05$ compared to that of obese control by MW test

Significant increase in absolute and relative epididymal adipose tissue weight were detected in obese versus intact control $(p<0.01)$. However, significant decrease in absolute and relative fat weight were detected in all dosing groups compared to obese control $(p<0.01$ or $p<0.05)$. More dramatic inhibition of fat deposition was seen in all of the mixed formulation groups relative to single formulation groups, with exception of 1:10, 6:1, 8:1 and $10: 1$ ratios $M$. charantia water extract + platycodin-D groups, in which non-significant inhibitory effects were observed relative to M. charantia water extract alone group (Table 4). In the obese control, absolute epididymal adipose tissue weight was $908.49 \%$ higher than in the intact control.

A significant decrease in serum adiponectin level was detected in the obese versus intact control $(p<0.01)$. However, a significant increase in serum adiponectin level was detected in all 
Table 3: Changes in blood glucose level after 28 days of test agent administration in genetically obese $\mathrm{db} / \mathrm{db}$ mice

\begin{tabular}{|c|c|c|c|}
\hline Groups & $\begin{array}{l}\text { At } 1 \text { day before initiation of } \\
\text { test article dosing }\end{array}$ & $\begin{array}{l}\text { At end of } 28 \text { days of test } \\
\text { article dosing }\end{array}$ & $\begin{array}{l}\text { Changes between one day before and end } \\
\text { of } 28 \text { days of test article dosing }\end{array}$ \\
\hline \multicolumn{4}{|l|}{ Control } \\
\hline Intact & $102.14 \pm 8.51$ & $108.43 \pm 10.03$ & $6.29 \pm 7.16$ \\
\hline Obese & $276.29 \pm 9.74^{*}$ & $360.57 \pm 19.55^{*}$ & $84.29 \pm 15.89^{*}$ \\
\hline$M C^{1)}$ & $276.14 \pm 8.34^{*}$ & $313.29 \pm 17.99^{\text {*.\# }}$ & $37.14 \pm 23.93^{* . \#}$ \\
\hline $\mathrm{PL}^{1)}$ & $277.14 \pm 16.21^{*}$ & $347.57 \pm 13.61^{*}$ & $70.43 \pm 21.01^{*}$ \\
\hline \multicolumn{4}{|l|}{$M C: P^{2)}$} \\
\hline$=1: 1$ & $274.14 \pm 11.48^{*}$ & $308.2922 .71^{\text {*.\# }}$ & $34.14 \pm 19.01^{\text {*.\# }}$ \\
\hline$=1: 2$ & $277.29 \pm 7.23^{*}$ & $304.86 \pm 24.91^{\text {*.\# }}$ & $27.57 \pm 21.88^{* \star * \#}$ \\
\hline$=1: 4$ & $276.14 \pm 8.51^{*}$ & $277.14 \pm 22.38^{\text {*.\# }}$ & $1.00 \pm 25.30^{\#}$ \\
\hline$=1: 6$ & $275.57 \pm 9.31^{*}$ & $324.29 \pm 14.38^{\star, \#}$ & $48.71 \pm 10.00^{* . \#}$ \\
\hline$=1: 8$ & $279.86 \pm 11.41^{*}$ & 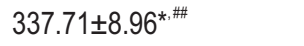 & $57.86 \pm 11.32^{*, \#}$ \\
\hline$=1: 10$ & $277.43 \pm 7.52^{*}$ & $346.86 \pm 15.02^{*}$ & $69.43 \pm 15.91^{*}$ \\
\hline$=2: 1$ & $276.57 \pm 7.52^{*}$ & $303.29 \pm 23.37^{\star * \#}$ & $26.71 \pm 29.35^{* \star \star \#}$ \\
\hline$=4: 1$ & $275.43 \pm 7.46^{*}$ & $302.14 \pm 11.70^{* \text { *\# }}$ & $26.71 \pm 12.13^{*, \#}$ \\
\hline$=6: 1$ & $275.14 \pm 5.05^{*}$ & $308.29 \pm 17.58^{\text {*.\# }}$ & $33.14 \pm 19.55^{\star \star \star \# ~}$ \\
\hline$=8: 1$ & $277.43 \pm 7.11^{*}$ & $307.71 \pm 11.28^{*, \#}$ & $29.29 \pm 11.87^{*, \#}$ \\
\hline$=10: 1$ & $276.86 \pm 13.66^{*}$ & $310.14 \pm 10.57^{* . \#}$ & $33.29 \pm 14.21^{* \text { *\# }}$ \\
\hline
\end{tabular}

Values are mean of seven replicates $\pm S D$; $\mathrm{mg} \mathrm{dl}^{-1}$; ${ }^{1)}$ Single formulation; ${ }^{2)}$ Mixed formulation; ${ }^{*} p<0.01$ and ${ }^{* *} p<0.05$ compared to that of intact control by MW test; ${ }^{\#} p<0.01$ and ${ }^{\#} p<0.05$ compared to that of obese control by MW test

Table 4 : Changes in the epididymal fat weight after 28 days of test agent administration in genetically obese $\mathrm{db} / \mathrm{db}$ mice

\begin{tabular}{|c|c|c|}
\hline Groups & Absolute weight (g) & Relative weight (\%) \\
\hline \multicolumn{3}{|l|}{ Control } \\
\hline Intact & $0.39 \pm 0.07$ & $1.38 \pm 0.23$ \\
\hline Obese & $3.90 \pm 0.41^{*}$ & $8.26 \pm 0.84^{*}$ \\
\hline$M C^{1)}$ & $3.18 \pm 0.23^{\text {*,\# }}$ & $7.080 .59^{* . \#}$ \\
\hline $\mathrm{PL}^{1)}$ & $2.92 \pm 0.25^{\star, \#}$ & $6.500 .69^{* . \#}$ \\
\hline \multicolumn{3}{|l|}{$M C: P^{2)}$} \\
\hline$=1: 1$ & $2.80 \pm 0.22^{*, \#}$ & $6.31 \pm 0.59^{\text {*.\# }}$ \\
\hline$=1: 2$ & $2.77 \pm 0.21^{\text {*.\# }}$ & $6.32 \pm 0.53^{\star, \#}$ \\
\hline$=1: 4$ & $2.40 \pm 0.38^{*, \#}$ & $5.54 \pm 0.96^{\star, \#}$ \\
\hline$=1: 6$ & $2.82 \pm 0.14^{\star, \#}$ & $6.29 \pm 0.37^{\star \# \#}$ \\
\hline$=1: 8$ & $2.90 \pm 0.18^{*}$ & $6.47 \pm 0.50^{\star, \#}$ \\
\hline$=1: 10$ & $2.93 \pm 0.20^{*}$ & $6.52 \pm 0.46^{*, \#}$ \\
\hline$=2: 1$ & $2.77 \pm 0.24^{\star, \#}$ & $6.21 \pm 0.59^{*, \#}$ \\
\hline$=4: 1$ & $2.85 \pm 0.18^{*, \#}$ & $6.55 \pm 0.55^{\text {*.\# }}$ \\
\hline$=6: 1$ & $3.10 \pm 0.16^{\text {*.\# }}$ & $6.93 \pm 0.39^{*}$ \\
\hline$=8: 1$ & $3.13 \pm 0.22^{*, \#}$ & $6.95 \pm 0.57^{*}$ \\
\hline$=10: 1$ & $3.16 \pm 0.13^{\text {*.\# }}$ & $7.04 \pm 0.35^{\star}$ \\
\hline
\end{tabular}

Values are mean of seven replicates $\pm \mathrm{SD} ;{ }^{1)}$ Single formulation; ${ }^{2)}$ Mixed formulation; Relative liver weight $(\%)=(($ Absolute organ weight / Body weight at sacrifice) $\times 100) ;{ }^{*} p<0.01$ compared to that of intact control by MW test; ${ }^{\#} p<0.01$ and ${ }^{\#} p<0.05$ compared to that of obese control by MW test

dosing groups compared to the obese control group $(p<0.01)$. More dramatic inhibition of decreased serum adiponectin levels was seen in all mixed formulation groups compared to single formulation groups, except for $M$. charantia water extract + platycodin-D in 8:1 and 10:1 ratios, in which non-significant beneficial inhibitory effects were observed compared to $M$. charantia water extract alone (Table 5). In obese control, the serum adiponectin level was $49.45 \%$ lower than in the intact control.
A significant decrease in epididymal adipose tissue adiponectin content was detected in the obese versus intact control $(p<0.01)$. However, a significant increase in epididymal adipose tissue adiponectin content was detected in all dosing groups compared to the obese control $(p<0.01)$. More dramatic inhibition of fat adiponectin was detected in all mixed formulation groups compared to the single formulation groups, except for $M$. charantia water extract + platycodin-D in 8:1 and 10:1 ratios, in 
Table 5 : Changes in adiponectin content, serum leptin levels and liver triglyceride after 28 days of test agent administration in genetically obese $d b / d b$ mice

\begin{tabular}{|c|c|c|c|c|}
\hline Groups & $\begin{array}{l}\text { Serum adiponectin level } \\
\left(\mu \mathrm{g} \mathrm{m}^{-1}\right)\end{array}$ & $\begin{array}{l}\text { Fat adiponectin contents } \\
(\% \text { control) }\end{array}$ & $\begin{array}{l}\text { Serum leptin level } \\
\left(\mathrm{ng} \mathrm{ml}^{-1}\right)\end{array}$ & $\begin{array}{l}\text { Liver triglyceride contents } \\
\text { ( } \mathrm{mg} \mathrm{g}^{-1} \text { liver) }\end{array}$ \\
\hline \multicolumn{5}{|l|}{ Control } \\
\hline Intact & $28.26 \pm 1.68$ & $266.86 \pm 21.81$ & $3.03 \pm 0.68$ & $29.93 \pm 1.78$ \\
\hline Obese & $14.29 \pm 1.43^{*}$ & $100.00 \pm 0.00^{*}$ & $19.19 \pm 1.49^{*}$ & $45.87 \pm 3.44^{*}$ \\
\hline$M C^{1)}$ & $17.16 \pm 0.69^{* . \#}$ & $119.71 \pm 9.14^{*, \#}$ & $16.46 \pm 1.85^{\star}$ & $39.64 \pm 3.21^{*, \#}$ \\
\hline $\mathrm{PL}^{11}$ & $17.66 \pm 1.10^{*, \#}$ & $124.43 \pm 7.70^{\text {*.\# }}$ & $14.43 \pm 1.78^{\text {*.\# }}$ & $37.30 \pm 3.75^{\star . \#}$ \\
\hline \multicolumn{5}{|l|}{$M C: P^{2)}$} \\
\hline$=1: 1$ & $19.73 \pm 1.74^{*, \#}$ & $125.14 \pm 4.67^{*, \#}$ & $13.94 \pm 1.52^{*, \#}$ & $34.80 \pm 1.62^{*, \#}$ \\
\hline$=1: 2$ & $20.49 \pm 1.21^{\text {*\#\# }}$ & $131.86 \pm 8.90^{*, \#}$ & $13.10 \pm 1.31^{*, \#}$ & $34.39 \pm 1.78^{*, \#}$ \\
\hline$=1: 4$ & $22.76 \pm 1.21^{\text {*\# }}$ & $154.57 \pm 22.46^{*, \#}$ & $10.47 \pm 1.14^{\text {*\# }}$ & $31.94 \pm 1.60^{* * . \#}$ \\
\hline$=1: 6$ & $20.23 \pm 1.94^{*, \#}$ & $132.43 \pm 6.43^{\star, \#}$ & $12.84 \pm 1.22^{*, \#}$ & $34.84 \pm 2.80^{*, \#}$ \\
\hline$=1: 8$ & $19.50 \pm 1.24^{*, \#}$ & $127.43 \pm 9.86^{*, \#}$ & $13.23 \pm 2.07^{\text {*\#\# }}$ & $35.07 \pm 2.15^{\star \star \#}$ \\
\hline$=1: 10$ & $17.98 \pm 1.09^{* \#}$ & $126.71 \pm 12.26^{\text {*\#\# }}$ & $14.14 \pm 1.32^{* . \#}$ & $36.26 \pm 3.80^{*, \#}$ \\
\hline$=2: 1$ & $19.66 \pm 1.37^{\text {*.\# }}$ & $133.86 \pm 7.03^{\text {*\# }}$ & $12.67 \pm 0.81^{\text {*.\# }}$ & $34.36 \pm 2.80^{* . \#}$ \\
\hline$=4: 1$ & $20.53 \pm 2.35^{\text {*\# }}$ & $135.43 \pm 12.14^{\text {*\# }}$ & $13.61 \pm 1.08^{*, \#}$ & $34.571 .17^{\text {*\# }}$ \\
\hline$=6: 1$ & $18.51 \pm 1.10^{*, \#}$ & $128.43 \pm 9.43^{\text {*.\# }}$ & $14.53 \pm 1.20^{* \# \#}$ & $35.70 \pm 3.81^{\text {*\#\# }}$ \\
\hline$=8: 1$ & $17.49 \pm 1.56^{* \#}$ & $122.86 \pm 9.55^{\star, \#}$ & $14.77 \pm 1.01^{\text {*\#\# }}$ & $37.97 \pm 2.52^{* . \#}$ \\
\hline$=10: 1$ & $17.42 \pm 1.14^{* \# \#}$ & $120.43 \pm 7.16^{*, \#}$ & $14.97 \pm 1.07^{\text {*\#\# }}$ & $38.37 \pm 2.36^{*, \#}$ \\
\hline
\end{tabular}

Values are mean of seven replicates $\pm S D,{ }^{1)}$ Single formulation; ${ }^{2)}$ Mixed formulation; ${ }^{*} p<0.01$ and ${ }^{* *} p<0.05$ compared to that of intact control by MW test; \# $p<0.01$ compared to that of obese control by MW test

which non-significant beneficial inhibitory effects were observed compared to M. charantia water extract alone (Table 5). In the obese control group, the epididymal adipose tissue adiponectin content was $62.53 \%$ lower than in the intact control group.

A significant increase in serum leptin level was detected in the obese versus intact control $(p<0.01)$. However, a significant decrease in serum leptin level was detected in all dosing groups compared to that of the obese control $(p<0.01$ or $p<0.05)$. More dramatic inhibition of serum leptin was detected in all mixed formulation groups compared to the single formulation groups, except for M. charantia water extract + platycodin-D in 6:1, 8:1 and 10:1 ratios, in which non-significant beneficial inhibitory effects were observed compared to $M$. charantia water extract alone (Table 5). In obese control, the serum leptin level was $533.49 \%$ higher than in the intact control.

A significant increase in liver triglycerides was detected in the intact control group compared to $\mathrm{db} / \mathrm{m}$ group $(\mathrm{p}<0.01)$. However, a significant decrease in liver triglycerides was detected in all dosing groups compared to obese control $(p<0.01)$. A more dramatic inhibition of increased liver triglycerides was detected in all mixed formulation groups compared to the single formulation groups, except for $M$. charantia water extract + platycodin-D in 8:1 and 10:1 ratios, in which non-significant beneficial inhibitory effects were observed compared to $M$. charantia water extract alone (Table 5). In obese control, the liver triglyceride level was $53.27 \%$ higher than in the intact control.
In the present study, the complementary and alternative treatments for obesity further investigated by mixing two potent hypoglycemic and hypolipemic agents: $M$. charantia water extract and platycodin-D. Bitter melon (Momordica charantia L.) is widely used for the treatment of diabetes. It has been shown that $M$. charantia can increase the number of beta cells (Ahmed et al., 1998). In another study, M. charantia acted like insulin and also promoted insulin release (Higashino et al., 1992). Some studies have also attributed hypoglycemic activity to an extra-pancreatic effect (Sarkar et al., 1996), including increased expression of GLUT4 transporter protein in muscles (Miura et al., 2004), increased glucose utilization in liver and muscles (Sarkar et al., 1996), inhibition of glucose-6-phosphatase and fructose-1, 6bisphosphatase in liver, and stimulation of red-cell and hepatic glucose-6-phosphate dehydrogenase activity (Shibib et al., 1993).

Recent research reports suggest that bitter melon extracts may ameliorate high-fat-diet-induced obesity and hyperlipidemia in animal models (Alam et al., 2015). Melon extracts have beneficial effects on body weight gain and abdominal fat deposition, early signs of obesity (Alam et al., 2015). Several reports suggest that bitter melon can reduce body weight in high-fat-diet-induced obesity in laboratory animals and bitter melon ( $0.75 \%$ of diet) supplementation showed a significant positive effect on the body weight gain and visceral fat mass in rats fed with high-fat diet (Chen and Li, 2005). This weightreduction effect may be a result of increased fatty acid oxidation, 
which ultimately facilitates weight reduction (Chen and Li, 2005). Moreover, bitter melon extract supplementation reduced peritoneal fat deposition in rats fed with high-fat diet (Chen and Li, 2005). In another study, bitter melon significantly decreased the weight of the epididymal white adipose tissue, visceral fat and adipose leptin of C57BL/6J mice fed with high-fat diet (Shih et al., 2008). Bano et al. (2011) reported that $2 \mathrm{ml}$ per day of aqueous extract of bitter melon significantly reduced body weight gain in rats. A recent study also showed that supplementation with seed oil of bitter melon reduced body weight and fat mass in mice fed with high-fat diet (Chen et al., 2012).

Approximately, 228 different compounds that have possible medicinal properties by themselves or in combination have been isolated from bitter melon fruit, seeds, leaves, stems, pericaps, endosperm, callus tissues and cotyledons (Singh et al., 2011). These materials contain hundreds of chemical compounds such as saponins, polysaccharides, proteins, triterpenoids, alkaloids, flavonoids, quinine, amino acids, fatty acids and trace elements (Zhang et al., 2016). Depending on the characteristics of the compounds isolated from M. charantia, they can be divided into several groups (e.g., phenolic and flavonoid compounds, cucurbitane-type triterpenoids, cucurbitane-type triterpene glycoside, oleanane-type triterpene saponins and insulin-like peptides) (Alam et al., 2015; Efird et al., 2014). Their beneficial effects on health have been partly attributed to these bioactive components of M. charantia (Zhang et al., 2016; Alam et al., 2015; Efird etal., 2014).

The effects of platycodin-D against obesity and hypolipemia have also been studied (Han et al., 2000, 2002) and it is generally accepted that the antiobesity activity of platycodin-D is mediated by the inhibition of intestinal absorption of dietary fat (via inhibition of pancreatic lipase activity) (Han et al., 2002). The antiobesity activity of platycodin-D is also associated with inhibition of acyl-coenzyme A (CoA) : cholesterol acyltransferase (ACAT) activity, antagonism of farnesoid $X$ receptor and formation of an insoluble complex between platycodin-D and cholesterol (Zhao et al., 2006).

Although the exact mechanism of action remain unknown, the favorable synergic effects of $M$. charantia water extract and platycodin-D are mediated by various factors, enclosing insulin-like activity, increased pancreatic beta cell expression, sympathetic activity and lipolysis, inhibition of the intestinal absorption of fats (via inhibition of pancreatic lipase), inhibition of hACAT activity, antagonism of farnesoid $\mathrm{X}$ receptor and formation of an insoluble complex.

Based on the results of this study, it is concluded that mixtures of $M$. charantia water extract and platycodin-D at appropriate ratios have obesity-inhibiting effects in obese diabetic mice. These synergic effects were reduced as the proportion of either $M$. charantia water extract or platycodin-D in the mixture increased, with the effects gradually becoming similar to those of a single formula as the amount of $M$. charantia water extract or platycodin-D increased. Among the 11 mixed $M$. charantia water extract + platycodin-D formulas tested in the present study, $M$. charantia water extract + platycodin-D 1:4 ratio had the most dramatic obesity- and hyperglycemia-inhibiting effects. The $M$. charantia water extract + platycodin-D mixture in 1:4 ratio showed relatively favorable obesity-inhibiting effects (especially against diabetes-related obesity) at reasonable dosages.

\section{References}

Ahmed, I., E. Adeghate, E. Cummings, A.K. Sharma and J. Singh: Beneficial effects and mechanism of action of Momordica charantia juice in the treatment of streptozotocin-induced diabetes mellitus in rat. Mol. Cell. Biochem., 261, 63-70 (2004).

Ahmed, I., E. Adeghate, A.K. Sharma, D.J. Pallot and J. Singh: Effects of Momordica charantia fruit juice on islet morphology in the pancreas of the streptozotocin-diabetic rat. Diabetes Res. Clin. Pract., 40, 145-151 (1998).

Alam, M.A., R. Uddin, N. Subhan, M.M. Rahman, P. Jain and H.M. Reza: Beneficial role of bitter melon supplementation in obesity and related complications in metabolic syndrome. J. Lipids, DOI : http:// dx.xi.org/10.1155/2015/496/96 (2015).

Bano, F., N. Akthar and H. Naz: Effect of the aqueous extracts of Momordica charantia on bodyweight of rats. J. Basic Appl. Sci., 7, 1-5(2011).

Basch, E., S. Gabardi and C. Ulbricht: Bitter melon (Momordica charantia): A review of efficacy and safety. Am. J. Hlth. Syst. Pharm., 60, 356-359 (2003).

Chen, P.H., G.C. Chen, M.F. Yang, C.H. Hsieh, S.H. Chuang, H.L. Yang, Y.H. Kuo, J.H. Chyuan and P.M. Chao: Bitter melon seed oilattenuated body fat accumulation in diet-induced obese mice is associated with cAMP-dependent protein kinase activation and cell death in white adipose tissue. J. Nut., 142, 1197-1204 (2012).

Chen, Q., L.L. Chan and E.T. Li: Bitter melon (Momordica charantia) reduces adiposity, lowers serum insulin and normalizes glucose tolerance in rats fed a high fat diet. J. Nut., 133, 1088-1093 (2003).

Chen, Q. and E.T.S. Li: Reduced adiposity in bitter melon (Momordica charantia) fed rats is associated with lower tissue triglyceride and higher plasma catecholamines. Br. J. Nut., 93, 747-754 (2005).

Danneman, P.J., S. Stein and S.O. Walshaw: Humane and practical implications of using carbon dioxide mixed with oxygen for anesthesia or euthanasia of rats. Lab. Anim. Sci., 47, 376-385 (1997).

Efird, J.T., Y.M. Choi, S.W. Davies, S. Mehra, E.J. Anderson and L.A. Katunga: Potential for improved glycemic control with dietary Momordica charantia in patients with insulin resistance and prediabetes. Int. J. Environ. Res. Public Hlth., 11, 2328-2345 (2014).

Fujita, H., H. Fujishima, J. Koshimura, M. Hosoba, N. Yoshioka, T. Shimotomai, T. Morii, T. Narita, M. Kakei and S. Ito: Effects of antidiabetic treatment with metformin and insulin on serum and adipose tissue adiponectin levels in db/db mice. Endocr. J., 52, 427-433 (2005).

Han, L.K., B.J. Xu, Y. Kimura, Y. Zheng and H. Okuda: Platycodi radix affects lipid metabolism in mice with high fat diet-induced obesity. J. Nut., 130, 2760-2764 (2000).

Han, L.K., Y.N. Zheng, B.J. Xu, H. Okuda and Y. Kimura: Saponins from 
platycodi radix ameliorate high fat diet-induced obesity in mice. $J$. Nut., 132, 2241-2245 (2002).

Higashino, H., A. Suzuki, Y. Tanaka and K. Pootakham: Hypoglycemic effects of Siamese Momordica charantia and Phyllanthus urinaria extracts in streptozotocin-induced diabetic rats (the 1st report). Nihon Yakurigaku Zasshi, 100, 415-421 (1992).

Inzucchi, S.E.: Oral antihyperglycemic therapy for type 2 diabetes. Scientific review. JAMA, 287, 360-372 (2002).

James, P.T., R. Leach, E. Kalamara and M. Shayeghi: The worldwide obesity epidemic. Obes. Res., 9, 228S-233S (2001).

Kim, K.S., E.K. Seo, Y.C. Lee, T.K. Lee, Y.W. Cho, O. Ezaki and C.H. Kim: Effect of dietary Platycodon grandiflorum on the improvement of insulin resistance in obese Zucker rats. J. Nut. Biochem., 11, 420424 (2000).

Mitchell, M., D.T. Armstrong, R.L. Robker and R.J. Norman: Adipokines: Implications for female fertility and obesity. Reproduction, 130, 583-597 (2005).

Miura, T., Y. Itoh, N. Iwamoto, M. Kato and T. Ishida: Suppressive activity of the fruit of Momordica charantia with exercise on blood glucose in type 2 diabetic mice. Biol. Pharm. Bull., 27, 248-250 (2004).

Neary, N.M., C.J. Small, M.R. Druce, A.J. Park, S.M. Ellis, N.M. Semjonous, C.L. Dakin, K. Filipsson, F. Wang, A.S. Kent, G.S. Frost, M.A. Ghatei and S.R. Bloom: Peptide YY3-36 and glucagonlike peptide-17-36 inhibit food intake additively. Endocrinology, 146, 5120-5127 (2005).

Park, J.Y. and Y.R. Heo: Effects of bitter melon (Momordica charantia) extracts on body weight change and lipid composition in C57/BL6J mice fed high fat diet. J. Human Ecol., 21, 113-121 (2011).

Park, S.H., S.K. Ko and S.H. Chung: Euonymus alatus prevents the hyperglycemia and hyperlipidemia induced by high-fat diet in ICR mice. J. Ethnopharmacol., 102, 326-335 (2005).

Rathi, S.S., J.K. Grover, V. Vikrant and N.R. Biswas: Prevention of experimental diabetic cataract by Indian Ayurvedic plant extracts. Phytother. Res., 16, 774-777 (2002).

Sahai, A., P. Malladi, X. Pan, R. Paul, H. Melin-Aldana, R.M. Green and P.F .Whitington: Obese and diabetic $\mathrm{db} / \mathrm{db}$ mice develop marked liver fibrosis in a model of nonalcoholic steatohepatitis: Role of short-form leptin receptors and osteopontin. Am. J. Physiol. Gastrointest. LiverPhysiol., 287, G1035-G1043 (2004).

Sakaue, H., A. Nishizawa, W. Ogawa, K. Teshigawara, T. Mori, Y. Takashima, T. Noda and M. Kasuga: Requirement for 3phosphoinositide-kependent dinase-1 (PDK-1) in insulin-induced glucose uptake in immortalized brown adipocytes. J. Biol. Chem., 278, 38870-38874 (2003).

Sarkar, S., M. Pranava and R. Marita: Demonstration of the hypoglycemic action of Momordica charantia in a validated animal model of diabetes. Pharmacol. Res., 33, 1-4 (1996).

Seufert, J., G. Lubben, K. Dietrich and P.C. Bates: A comparison of the effects of thiazolidinediones and metformin on metabolic control in patients with type 2 diabetes mellitus. Clin. Ther., 26, 805-818 (2004).

Sharma, K., P. McCue and S.R. Dunn: Diabetic kidney disease in the db/db mice. Am. J. Physiol. Renal Physiol., 284, F1138- F1144 (2003).

Shibib, B.A., L.A. Khan and R. Rahman: Hypoglycaemic activity of Coccinia indica and Momordica charantia in diabetic rats: Depression of the hepatic gluconeogenic enzymes glucose-6phosphatase and fructose-1,6-bisphosphatase and elevation of both liver and red-cell shunt enzyme glucose-6-phosphate dehydrogenase. Biochem. J., 292, 267-270 (1993).

Shih, C.C., C.H. Lin and W.L. Lin: Effects of Momordica charantia on insulin resistance and visceral obesity in mice on high-fat diet. Diabetes Res. Clin. Pract., 81, 134-143 (2008).

Singh, J., E. Cumming, G. Manoharan, H. Kalasz and E. Adeghate: Medicinal chemistry of the anti-diabetic effects of Momordica charantia: Active constituents and modes of actions. Open Med. Chem. J., 5, 70 (2011).

Wolf, G., S. Chen, D.C. Han and F.N. Ziyadeh: Leptin and renal disease. Am. J. Kidney Dis., 39, 1-11 (2002).

Yamauchi, T., J. Kamon, H. Waki, Y. Imai, N. Shimozawa, K. Hioki, S. Uchida, Y. Ito, K. Takakuwa, J. Matsui, M. Takata, K. Eto, Y. Terauchi, K. Komeda, M. Tsunoda, K. Murakami, Y. Ohnishi, T. Naitoh, K. Yamamura, Y. Ueyama, P. Froguel, S. Kimura, R. Nagai and T. Kadowaki: Globular adiponectin protected ob/ob mice from diabetes and ApoE-deficient mice from atherosclerosis. J. Biol. Chem., 278, 2461-2468 (2003).

Zhang, F., L. Lin and J. Xie: A mini-review of chemical and biological properties of polysaccharides from Momordica charantia. Int. J. Biol. Macromol., 92, 246-253 (2016).

Zhao, H.L., J.S. Sim, S.H. Shim, Y.W. Ha, S.S. Kang and Y.S. Kim: Cholesterol-lowering effect of platycodin $D$ in hypercholesterolemic ICR mice. Eur. J. Pharmacol., 537, 166-173 (2006).

Zimmet, P. : The burden of type 2 diabetes: Are we doing enough? Diabetes Metab., 29, 6S9-6S18 (2003). 